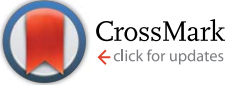

Cite this: RSC Adv., 2017, 7, 10791

\title{
Amidoximated poly(vinyl imidazole)-functionalized molybdenum disulfide sheets for efficient sorption of a uranyl tricarbonate complex from aqueous solutions $\uparrow$
}

\begin{abstract}
Liang Shen, ${ }^{a}$ Xiaoli Han, ${ }^{a}$ Jun Qian ${ }^{a}$ and Daoben Hua*ab
It is of strategic importance to capture uranium(vl) from aqueous solutions from the points of environment and energy. A new method is reported herein for efficient uranium(vi) capture from aqueous solutions by amidoximated poly(vinyl imidazole)-functionalized $\mathrm{MoS}_{2}$ sheets. Specifically, the sorbent is prepared by grafting amidoximated poly(vinyl imidazole) onto $\mathrm{MoS}_{2}$-sheets through covalent bonds. The sorption follows pseudo-second-order kinetics and the equilibrium can be reached within $30 \mathrm{~s}$. There is a large sorption capacity of $348.4 \mathrm{mg} \mathrm{g}^{-1}$ at $\mathrm{pH} 8.0$ and $298.15 \mathrm{~K}$. The sorbent shows good selectivity towards uranium(VI) over the coexisting ions in comparison with bare $\mathrm{MoS}_{2}$-sheets. In addition, the sorbent exhibits remarkable salt-resistant stability and can be regenerated efficiently after five cycles with high cycle efficiency. To the best of our knowledge, this is the first report on $\mathrm{MoS}_{2}$ sheets for uranium(vi) sorption with high efficiency from aqueous solution.
\end{abstract}

Received 11th December 2016 Accepted 30th January 2017

DOI: $10.1039 / c 6 r a 28051 j$

rsc.li/rsc-advances investigated, such as mesoporous carbon, ${ }^{\mathbf{1 1 , 1 2}}$ chelating polymers, ${ }^{\mathbf{1 3 , 1 4}}$ graphene oxides, ${ }^{\mathbf{1 5}-\mathbf{1 7}}$ metal sulfides, ${ }^{\mathbf{1 8 , 1 9}}$ engineered proteins, ${ }^{20}$ and metal-organic frameworks. ${ }^{21}$ Although considerable achievements have been made, it is still a challenge to effectively extract uranium from aqueous solutions due to the complexity of environment, such as low concentration, a large number of coexisting ions, and high salinity. ${ }^{2,22}$ Therefore, it is still important to develop new materials for uranium capture from aqueous solutions.

Layered $\mathrm{MoS}_{2}$ is one kind of graphene-like two-dimensional materials with a structure of "S-Mo-S" sandwich. Ascribed to excellent mechanical properties and chemical stability, ${ }^{23-26}$ $\mathrm{MoS}_{2}$ has gained significant interest for several applications: electronic transistors, ${ }^{24,27}$ lubrication, ${ }^{26}$ catalysis, ${ }^{25}$ energy storage, ${ }^{28}$ sensors, ${ }^{29}$ and sorption. ${ }^{30,31}$ For instance, Chao et al. ${ }^{30}$ prepared graphene-like layered $\mathrm{MoS}_{2}$ by hydrothermal method for efficiently eliminating doxycycline antibiotic from aqueous solution; and Massey et al. ${ }^{31}$ reported hierarchical microspheres of $\mathrm{MoS}_{2}$ nanosheets for fast and efficient removal of dyes from the wastewater. Obviously, $\mathrm{MoS}_{2}$-sheets may be promising matrix materials for efficient uranium sorption from aqueous solution. However, the application of $\mathrm{MoS}_{2}$-sheets for metal sorption, especially for radionuclide treatment, has not been explored until now.

Uranyl tricarbonate complex $\left[\mathrm{UO}_{2}\left(\mathrm{CO}_{3}\right)_{3}\right]^{4-}$ is the most abundant species of uranium(vI) in aqueous solutions with high $\left[\mathrm{CO}_{3}{ }^{2-}\right]$ and $\mathrm{pH} .{ }^{32}$ Zeng et al. ${ }^{33}$ recently grafted cationic poly(amidoxime) onto polypropylene nonwoven fabric for extraction of $\left[\mathrm{UO}_{2}\left(\mathrm{CO}_{3}\right)_{3}\right]^{4-}$ from aqueous solution. We noticed that 


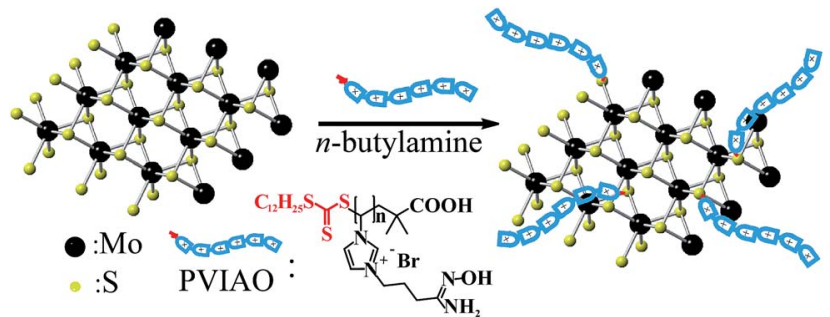

Scheme 1 The schematic for synthesis of PVIAO-modified $\mathrm{MoS}_{2}-$ sheets.

positively charged sorbents can attract the negative uranium(vi) complex while repelling the other cations, subsequently leading to a higher sorption selectivity and faster sorption rate. ${ }^{33,34}$ Inspired by this finding, we herein synthesized amidoximated poly(vinyl imidazole)-functionalized $\mathrm{MoS}_{2}$ sheets $\left(\mathrm{MoS}_{2}\right.$-PVIAO) for uranium(vi) capture from aqueous solutions (Scheme 1).

Specifically, the sorbent was prepared by one-pot reaction of amidoximated poly(vinyl imidazole) (PVIAO) and $\mathrm{MoS}_{2}$-sheets in the presence of $n$-butylamine. During the reaction, the terminal trithiocarbonate groups of PVIAO were converted into thiol groups by aminolysis reaction, ${ }^{35}$ and the polymers can graft onto exfoliated $\mathrm{MoS}_{2}$-sheets through disulphide bonds ${ }^{29,36}$ and Coulomb interaction. ${ }^{37}$ The high surface area of $\mathrm{MoS}_{2}$ sheets would bring about a faster sorption. ${ }^{31}$ Furthermore, the positive charges of PVIAO can improve the sorption selectivity of uranyl tricarbonate complex. ${ }^{33,34}$ Therefore, it is expected that the sorbent $\mathrm{MoS}_{2}$-PVIAO could be used for effective uranium(vI) sorption from aqueous solutions.

\section{Experimental}

\section{Materials and methods}

1-Vinylimidazole (VI, CP), 2,2'-azoisobutyronitrile (AIBN, CP), sodium sulfite anhydrous $\left(\mathrm{Na}_{2} \mathrm{SO}_{3}, \mathrm{AR}\right)$ and $n$-butylamine $(99 \%$, AR) were bought from Sinopharm Chemical Reagent Co., Ltd. 4-Bromobutyronitrile (97\%) and hydroxylamine hydrochloride $\left(\mathrm{NH}_{2} \mathrm{OH} \cdot \mathrm{HCl}, 99 \%\right)$ were obtained from J\&K Chemical Co., Ltd. $n$-Butyllithium solution $\left(1.6 \mathrm{~mol} \mathrm{~L}^{-1}\right)$ in hexane was purchased from Adamas Reagent Co., Ltd. $\mathrm{MoS}_{2}(98.5 \%$, GR) was purchased from Acros Organics Co., Ltd.

VI was pretreated by reduced pressure distillation and stored at $-18{ }^{\circ} \mathrm{C}$ prior to use. AIBN was purified by recrystallization from $95 \%$ ethanol. $\left(\mathrm{UO}_{2}\left(\mathrm{NO}_{3}\right)_{2} \cdot 6 \mathrm{H}_{2} \mathrm{O}\right)$, (Fluka, $\mathrm{AR}$ ) was dissolved to prepare the stock solutions of uranyl ions. S-1Dodecyl- $S^{\prime}$ - $\left(\alpha, \alpha^{\prime}\right.$-dimethyl- $\alpha^{\prime \prime}$-acetic acid)trithiocarbonate (DDATC) was prepared in accordance to the previous literature ${ }^{38}$ (Fig. S1, ESI†). All other reagents and chemicals were used as received. The characterization methods were shown in ESI. $\dagger$

\section{Synthesis of $\mathrm{MoS}_{2}$-PVIAO}

$\mathrm{MoS}_{2}$-sheets were first exfoliated by intercalation with $n$-butyllithium $^{36}\left(\mathrm{ESI}_{\dagger} \dagger\right)$, and PVIAO $\left(M_{\mathrm{n}}=2900 \mathrm{~g} \mathrm{~mol}^{-1}\right.$, PDI $\left.=1.08\right)$ was prepared by RAFT polymerization (Fig. S2, ESI $\dagger$ ). A typical synthetic method for $\mathrm{MoS}_{2}$-PVIAO was shown as follows:
Table 1 Synthesis recipes of $\mathrm{MOS}_{2}-\mathrm{PVIAO}$ and graft degree of PVIAO

\begin{tabular}{llllll}
\hline Sample & $\begin{array}{l}\mathrm{MoS}_{2} \text {-sheets } \\
(\mathrm{g})\end{array}$ & $\begin{array}{l}\mathrm{Na}_{2} \mathrm{SO}_{3} \\
(\mathrm{~g})\end{array}$ & $\begin{array}{l}n \text {-Butylamine } \\
(\mathrm{mL})\end{array}$ & $\begin{array}{l}\text { PVIAO } \\
(\mathrm{g})\end{array}$ & $\mathrm{GD}^{a}$ \\
\hline $\mathrm{MoS}_{2}$-PVIAO-1 & 0.20 & 1.0 & 2.0 & 0.10 & $10.0 \%$ \\
$\mathrm{MoS}_{2}$-PVIAO-2 & 0.20 & 1.0 & 2.0 & 0.20 & $17.1 \%$ \\
$\mathrm{MoS}_{2}$-PVIAO-3 & 0.20 & 1.0 & 2.0 & 0.50 & $53.7 \%$ \\
${ }^{a}$ Graft degree was determined by TGA curve. & &
\end{tabular}

specifically, $\mathrm{MoS}_{2}$-sheets $(0.2 \mathrm{~g}, 1.25 \mathrm{mmol})$ were dispersed in $200 \mathrm{~mL}$ of ultrapure water. Then, $\mathrm{Na}_{2} \mathrm{SO}_{3}(1.0 \mathrm{~g}, 7.93 \mathrm{mmol})$ and PVIAO ( $0.2 \mathrm{~g}, 0.07 \mathrm{mmol})$ were added into suspension with continuously stirring under an argon atmosphere for $0.5 \mathrm{~h}$ at room temperature. $2.0 \mathrm{~mL}$ of $n$-butylamine was injected into the mixture and then sonicated for $2 \mathrm{~h}$. After the mixture was agitated for extra $20 \mathrm{~h}$, it was dialyzed against continuous water flow with dialysis membranes $(\mathrm{MWCO}=10 \mathrm{~K})$. Then it was lyophilized to give the final black powder. For comparison, $\mathrm{MoS}_{2}$-PVIAO samples with different grafting degree (GD) were also prepared by the similar experiment and the recipes were shown in Table 1.

\section{Sorption experiments}

The distribution of uranium(vI) species was calculated using Medusa program under different $\mathrm{pH}$ conditions (Fig. S3A, ESI $†$ ), and the result showed uranyl tricarbonate complex is the dominant species of uranium(vi) in aqueous solutions when $\mathrm{pH}$ $\geq$ 8.0. Therefore, all sorption experiments were conducted at $\mathrm{pH} 8.0$ and $298.15 \mathrm{~K}$ in polyethylene tubes. The $\mathrm{pH}$ values were adjusted by $2.0 \mathrm{~mol} \mathrm{~L}^{-1} \mathrm{HNO}_{3}$ and $2.0 \mathrm{~mol} \mathrm{~L}^{-1} \mathrm{Na}_{2} \mathrm{CO}_{3}$ solutions. The uranyl concentrations before and after sorption were analyzed by ICP-MS. The equilibrium sorption amount $\left(q_{\mathrm{e}}\right)$ and sorption efficiency (SE) were determined based on eqn (1) and (2), respectively:

$$
\begin{gathered}
q_{\mathrm{e}}=\left(C_{0}-C_{\mathrm{e}}\right) \frac{V}{M} \\
\mathrm{SE}(\%)=\frac{C_{0}-C_{\mathrm{e}}}{C_{0}} \times 100
\end{gathered}
$$

where $C_{0}$ and $C_{\mathrm{e}}\left(\mathrm{mg} \mathrm{L}^{-1}\right)$ represent the initial and final uranium concentrations, respectively. $M(\mathrm{~g})$ represents the desiccative sorbent weight, and $V$ (L) denotes the volume of aqueous solution.

The first set of experiments was performed to demonstrate the effect of sorbent dose $\left(0.03-2.00 \mathrm{~g} \mathrm{~L}^{-1}\right)$ on uranium(vI) sorption with an initial concentration of $5.0 \times 10^{-5} \mathrm{~mol} \mathrm{~L}^{-1}$. After shaking for $24 \mathrm{~h}$ until sorption equilibrium, the solid phase was separated by centrifugation.

The second set of experiments was conducted to check into the effect of contact time on the sorption of uranium(vi). Since the sorption equilibrium was achieved in a short time, the mixture was filtered immediately after sorption within different time.

The third set of experiments was carried out to examine the influence of various coexisting ions, salinity and different uranyl 
initial concentrations $\left(5.0 \times 10^{-5}\right.$ to $\left.3.3 \times 10^{-4} \mathrm{~mol} \mathrm{~L}^{-1}\right)$. A typical sorption procedure was described as follows: the sorbents $(1.0 \mathrm{mg})$ were added into $5.0 \mathrm{~mL}$ of uranium(vi) solution and the mixture was shaking for $8 \mathrm{~h}$ until sorption equilibrium, and the sorbents were then removed by centrifugation. In addition, the total concentration of $\mathrm{CO}_{3}{ }^{2-}$ was close to $6.0 \times 10^{-3} \mathrm{~mol} \mathrm{~L}^{-1}$ when $\mathrm{pH}$ was adjusted to $\sim 8.0$ with $\mathrm{Na}_{2} \mathrm{CO}_{3}$ solutions. According to calculation with Medusa program, there is no precipitation of uranium(vi) in the solution under the experimental conditions (i.e. $\mathrm{pH} 8.0,\left[\mathrm{CO}_{3}{ }^{2-}\right]=6.0 \times 10^{-3} \mathrm{~mol} \mathrm{~L}^{-1}$, and $[\mathrm{U}]=3.3 \times$ $10^{-4} \mathrm{~mol} \mathrm{~L}^{-1}$ ) (Fig. S3B, ESI $\dagger$ ).

\section{Desorption and regeneration experiment}

The desorption and regeneration studies were conducted to assess the recyclability of the sorbent. The as-prepared $\mathrm{MoS}_{2}$ PVIAO (17.1\%) powders $(3.0 \mathrm{mg})$ were added into $10.0 \mathrm{~mL}$ of uranium(vI) solution under continuous oscillation. After saturated sorption, the mixture was dialyzed in $\mathrm{HCl}$ solution $\left(0.1 \mathrm{~mol} \mathrm{~L}{ }^{-1}, 200 \mathrm{~mL}\right)$ and $\mathrm{NaHCO}_{3}$ solution $\left(1.0 \mathrm{~mol} \mathrm{~L}{ }^{-1}, 200\right.$ $\mathrm{mL})$ to remove uranium(vi), respectively. Ultrapure water (200 $\mathrm{mL}$ ) was then used to wash for three times until neutral and lyophilized for reuse.

\section{Simulated seawater experiment}

Simulated seawater experiments were conducted with two models according to the ref. 12. Specifically, the simulated seawater was comprised of $0.438 \mathrm{~mol} \mathrm{~L}^{-1} \mathrm{NaCl}, 2.297 \mathrm{mmol} \mathrm{L}^{-1}$ $\mathrm{NaHCO}_{3}$ and $0.034 \mathrm{mmol} \mathrm{L}^{-1}$ uranyl nitrate in ultrapure water. In addition, $\mathrm{CaCl}_{2}\left(0.01 \mathrm{mmol} \mathrm{L}^{-1}\right)$ was also added into the solution to investigate the effect of calcium ions on sorption. The $\mathrm{pH}$ was adjusted to $8.0 . \mathrm{MoS}_{2}$-PVIAO (17.1\%) $(1.0 \mathrm{mg})$ and $5.0 \mathrm{~mL}$ of stock solution were placed in polyethylene tubes. The mixture was shaken for different period of time at room temperature. Finally the sorbents were removed by filtration.

\section{Results and discussion}

\section{Characterization of $\mathrm{MoS}_{2}$-PVIAO}

In order to synthesize $\mathrm{MoS}_{2}$-PVIAO, $\mathrm{MoS}_{2}$-sheets were first prepared by intercalating exfoliation of $\mathrm{MoS}_{2}$ powder with $n$ butyllithium, ${ }^{36}$ and PVIAO was synthesized by controlled polymerization of VI and subsequent reaction with 4-bromobutyronitrile and with hydroxylamine, respectively (ESI $\dagger$ ). $\mathrm{MoS}_{2^{-}}$ PVIAO was then prepared by grafting PVIAO onto $\mathrm{MoS}_{2}$-sheets in the presence of $n$-butylamine. During the reaction, the terminal trithiocarbonate groups of PVIAO chains were converted into thiol groups, and the chains could connect with vacancy defects of exfoliated $\mathrm{MoS}_{2}$-sheets through disulphide bonds and Coulomb interaction.

The morphological features of $\mathrm{MoS}_{2}$-PVIAO were characterized by TEM and XRD. In comparison with $\mathrm{MoS}_{2}$ (Fig. 1A), the sheets of $\mathrm{MoS}_{2}$-PVIAO present obvious nano-sheets structure and the interlayer distance was about $1.0 \mathrm{~nm}$ (Fig. 1B and the inset). Furthermore, the better dispersion of $\mathrm{MoS}_{2}$-PVIAO indicated the successful graft of PVIAO onto $\mathrm{MoS}_{2}$-sheets (Fig. 1C). This point was further demonstrated by XRD patterns. After

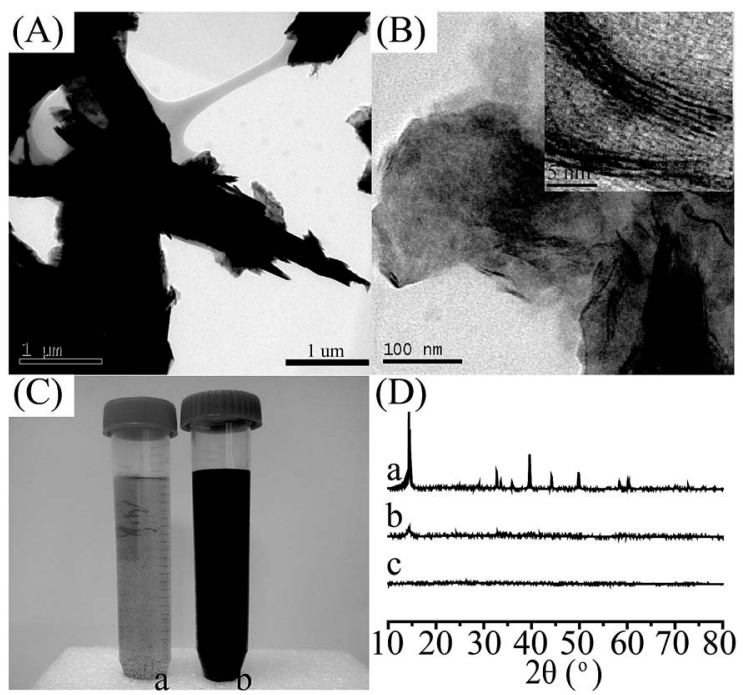

Fig. 1 (A) TEM images of $\mathrm{MoS}_{2}$ (scale bar: $1 \mu \mathrm{m}$ ); (B) TEM images of $\mathrm{MOS}_{2}$-PVIAO (scale bar: $100 \mathrm{~nm}$ ). Inset: an edge of individual $\mathrm{MoS}_{2^{-}}$ PVIAO (scale bar: $5 \mathrm{~nm}$ ); (C) pictures of (a) $\mathrm{MoS}_{2}$-sheets and (b) $\mathrm{MoS}_{2}$ PVIAO (17.1\%) (2.0 mg of solid was dispersed in $10.0 \mathrm{~mL}$ of water). (D) XRD powder patterns for (a) $\mathrm{MoS}_{2}$, (b) $\mathrm{MoS}_{2}$-sheets, and (c) $\mathrm{MoS}_{2^{-}}$ PVIAO (17.1\%)

exfoliation and modification of $\mathrm{MoS}_{2}$, the characteristic peaks at $2 \theta=13^{\circ}$ and $41^{\circ}$ for $\mathrm{MoS}_{2}$ (JCPDS card 37-1492) disappeared (Fig. 1D), suggesting the crystal structure was destroyed by polymer chains.

The chemical components of $\mathrm{MoS}_{2}$-PVIAO (17.1\%) were characterized by XPS and FT-IR spectra. XPS scans showed the elements in $\mathrm{MoS}_{2}$-sheets and $\mathrm{MoS}_{2}$-PVIAO (17.1\%), respectively (Fig. 2A). Compared with $\mathrm{MoS}_{2}$-sheets (Fig. 2A, trace a), $\mathrm{MoS}_{2^{-}}$ PVIAO (17.1\%) (Fig. 2A, trace b) showed the new peak for N (1s) element, which could be curve-fitted with three peak components ascribed to $\mathrm{C}-\mathrm{N}, \mathrm{C}=\mathrm{N}$, and $\mathrm{N}-\mathrm{O}$ species (Fig. 2B), suggesting the successful grafting of PVIAO onto $\mathrm{MoS}_{2}$-sheets. The chemical structures of $\mathrm{MoS}_{2}$-PVIAO (17.1\%) were confirmed by FT-IR spectra (Fig. 2C, trace b). Compared with $\mathrm{MoS}_{2}$-sheets (Fig. 2C, trace a), the characteristic bands of $\mathrm{C}=\mathrm{N}$ (ring, 1539 $\left.\mathrm{cm}^{-1}\right), \mathrm{N}-\mathrm{O}\left(835 \mathrm{~cm}^{-1}\right)$ occurred for $\mathrm{MoS}_{2}$-PVIAO (Fig. 2C, trace b). Moreover, $\mathrm{MoS}_{2}$-PVIAO were positively charged after the graft of cationic polymer (Fig. S4, ESI $\dagger$ ), and the more graft content, the higher zeta potential, which would be helpful for the sorption of negative uranyl complex.

In order to investigate chemical contents of $\mathrm{MoS}_{2}$-PVIAO, thermogravimetric analysis was carried out. The result was shown in Fig. 2D. There were two obvious stages during the process of mass loss: crystal water desorbed at stage I, whose weight percentage was approximately $2.2 \%$; stage II was the process of decomposition of PVIAO, which can be used to determine the graft contents as $10.0 \%, 17.1 \%$ and $53.7 \%$ for $\mathrm{MoS}_{2}$-PVIAO, respectively.

\section{Effects of sorbent dose on sorption}

The influence of sorbent amount on uranium(vi) sorption was conducted at $\mathrm{pH} 8.0$ and $298.15 \mathrm{~K}$. The result was shown in 


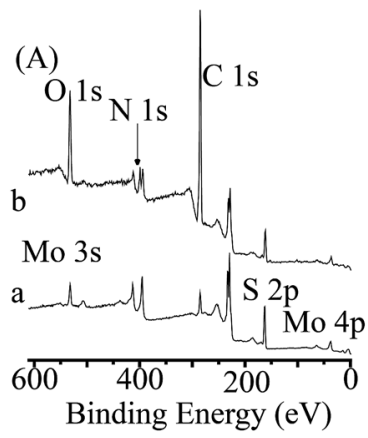

(C)
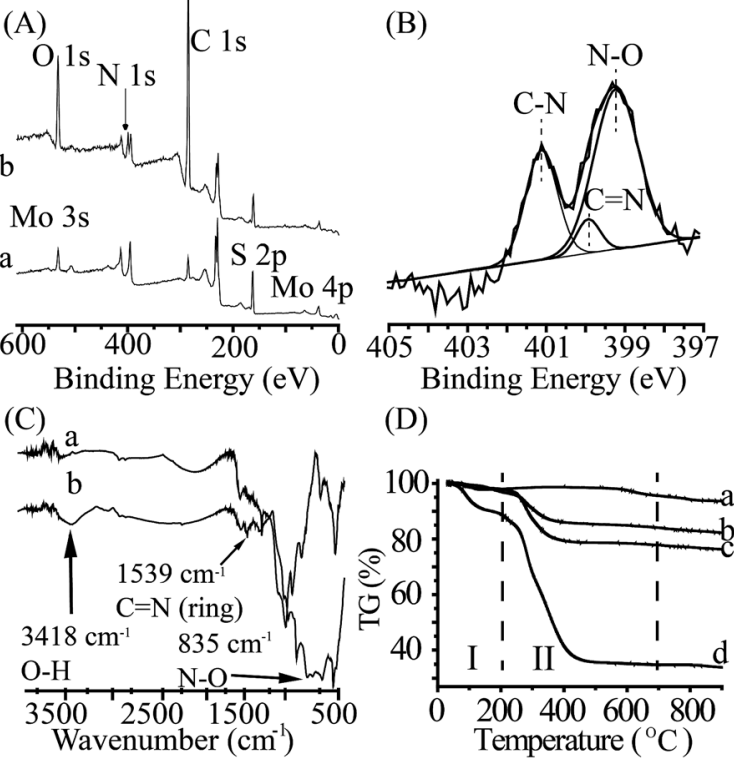

(D)

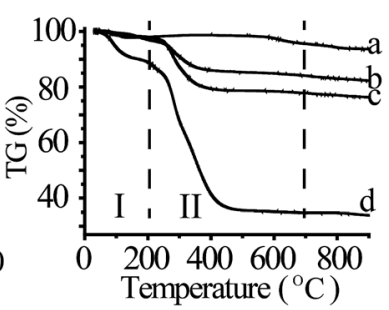

Fig. 2 (A) XPS spectra of (a) $\mathrm{MoS}_{2}$-sheets and (b) $\mathrm{MOS}_{2}$-PVIAO (17.1\%); (B) XPS spectra of N 1s of $\mathrm{MoS}_{2}-\mathrm{PVIAO}(17.1 \%)$; (C) FT-IR spectra of (a) $\mathrm{MoS}_{2}$-sheets and (b) MoS ${ }_{2}-\mathrm{PVIAO}(17.1 \%)$. (D) TGA curves of (a) $\mathrm{MoS}_{2}-$ sheets, (b) $\mathrm{MoS}_{2}-\mathrm{PVIAO}$ (10.0\%), (c) MoS $\mathrm{M}_{2}$ PVIAO (17.1\%) and (d) $\mathrm{MoS}_{2}-$ PVIAO (53.7\%).

Fig. 3A. With the increase of sorbent dose, sorption efficiency was first increased and then decreased, and there is a maximum value at $0.20 \mathrm{~g} \mathrm{~L}^{-1}$. The result may be attributed that the stacking of $\mathrm{MoS}_{2}$-sheets at high concentration, resulting in a reduction of the sorption efficiency. To confirm the speculation, SEM and particle
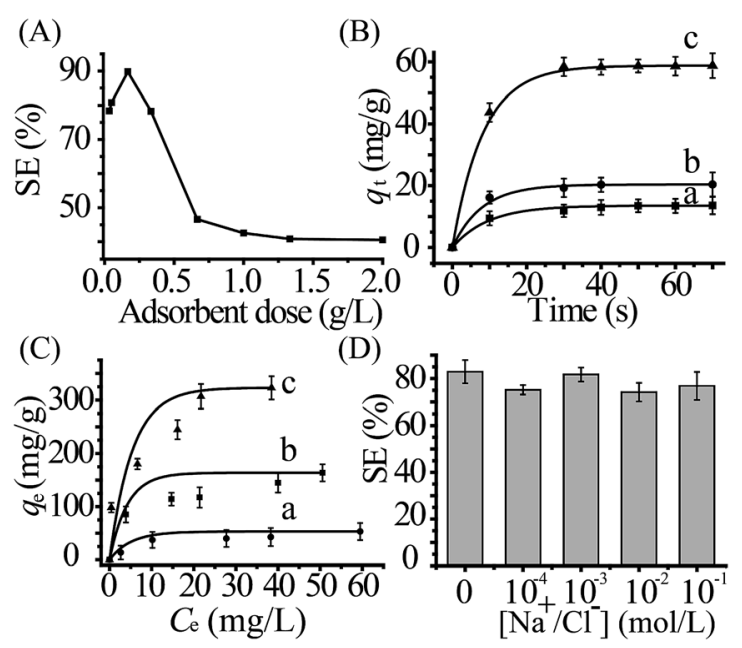

Fig. 3 (A) The relationship between sorption efficiency and sorbent dose $\left(0-60 \mathrm{mg} \mathrm{L}^{-1}\right)$ in uranium(VI) sorption by $\mathrm{MoS}_{2}$-PVIAO (17.1\%). (B) Effects of contact time on uranium(vi) sorption with $0.2 \mathrm{~g} \mathrm{~L}^{-1}$ sorbent dose: (a) $\mathrm{MoS}_{2}$-sheets, (b) $\mathrm{MoS}_{2}$-PVIAO (10.0\%) and (c) MoS $-\mathrm{PVIAO}$ (17.1\%). (C) Sorption isotherm plots for uranium(vi) sorption with $0.2 \mathrm{~g}$ $\mathrm{L}^{-1}$ sorbent dose: (a) $\mathrm{MOS}_{2}$-sheets, (b) $\mathrm{MOS}_{2}-\mathrm{PVIAO}(17.1 \%$ ) and (c) $\mathrm{MoS}_{2}$-PVIAO (53.7\%). (D) The sorption efficiency of uranium(vI) by $\mathrm{MoS}_{2}$-PVIAO $\left(17.1 \%, 0.2 \mathrm{~g} \mathrm{~L}^{-1}\right.$ sorbent dose) in the presence of $\mathrm{Na}^{+} / \mathrm{Cl}^{-}$ with different concentrations (experimental condition: $5.0 \mathrm{~mL}$ solution, $\mathrm{pH} 8.0,5.0 \times 10^{-5} \mathrm{~mol} \mathrm{~L}^{-1}$ uranium(vI) and $298.15 \mathrm{~K}$ ). size distributions were conducted for $\mathrm{MoS}_{2}$-PVIAO (17.1\%) with different sorbent doses (Fig. S5, ESI $\dagger$ ). The aggregation of the sorbents can be recorded obviously and particle size distributions were increasing with the sorbent dose. Therefore, the optimum sorbent dose of $0.20 \mathrm{~g} \mathrm{~L}^{-1}$ was selected for next experiments.

\section{Sorption kinetics}

To investigate the sorption rate, the kinetic experiments were performed at $\mathrm{pH} 8.0$ and $298.15 \mathrm{~K}$ with the optimum sorbent dose of $0.20 \mathrm{~g} \mathrm{~L}^{-1}$. The result was shown in Fig. 3B. The effect of contact time $(t)$ on uranium(vi) sorption showed that all of the sorption reached equilibrium within $30 \mathrm{~s}$, and the more grafting polymer, the more equilibrium amount.

Pseudo-first-order equation ${ }^{39}$ and pseudo-second-order equation $^{\mathbf{4 0 , 4 1}}$ were used to simulate the sorption kinetics (Fig. S6, ESI $\dagger$ ), and the kinetics parameters were listed in Table 2. Kinetic profiles were appropriately described by pseudo-second-order model due to the larger correlation coefficients $\left(R^{2}\right)$ and the more accurate calculated $q_{\mathrm{e}}$. Importantly, there was a remarkably larger rate constant $k_{2}$ of $\mathrm{MoS}_{2}$-PVIAO compared with the reference results (Table $\mathrm{S} 1, \mathrm{ESI} \dagger$ ). It was also noticed that the $k_{2}$ for $\mathrm{MoS}_{2}$-PVIAO (10.0\%) was slightly larger than $\mathrm{MoS}_{2}$-sheets, implying a more rapid sorption, which may be ascribed to electrostatic attraction between the positive sorbent and negative uranyl tricarbonate complex besides the good covalency between uranium and sulfur. ${ }^{18,19}$ However, the $k_{2}$ for $\mathrm{MoS}_{2}$-PVIAO (17.1\%) was much smaller than $\mathrm{MoS}_{2}$-PVIAO (10.0\%), which may be attributed to the weaken interaction of $\mathrm{MoS}_{2}$ with uranium(vI) by relatively more polymer chains.

\section{Sorption isotherm}

To understand sorption capacity, the isotherm studies were carried out with the concentrations of uranium(vi) from $5.0 \times$ $10^{-5}$ to $3.3 \times 10^{-4} \mathrm{~mol} \mathrm{~L}^{-1}$ at $298.15 \mathrm{~K}$ and $\mathrm{pH}$ 8.0. The relationship between $q_{\mathrm{e}}$ and $C_{\mathrm{e}}$ was shown in Fig. 3C. The sorption data were simulated with Langmuir and Freundlich models ${ }^{\mathbf{4 2 , 4 3}}$ (Fig. S7, ESI†).

The correlation coefficients and parameters were summarized in Table 3 . The sorption process was more appropriately described by Langmuir model according to the larger correlation coefficients $\left(R^{2}\right)$. The result may be ascribed to that active sites homogenously distribute on the surfaces, thereby leading to monolayer sorption. The capacity $q_{\max }$ of $\mathrm{MoS}_{2}$-PVIAO (53.7\%) could reach $348.4 \mathrm{mg} \mathrm{g}^{-1}$, which was far larger than that of $\mathrm{MoS}_{2}$-sheets $\left(57.97 \mathrm{mg} \mathrm{g}^{-1}\right.$ ). In addition, there was a larger $b$ value for $\mathrm{MoS}_{2}$-PVIAO than that for $\mathrm{MoS}_{2}$-sheets, which may be ascribed to the Coulomb force between cationic sorbents and negative uranyl complex.

\section{Effect of coexisting ions and salinity on uranium(vI) sorption}

Considering that certain metals $\left(\mathrm{Fe}^{3+}, \mathrm{Zn}^{2+}\right.$, etc. $)$ may form precipitation at high $\left[\mathrm{CO}_{3}{ }^{2-}\right]$ and $\mathrm{pH}^{\mathbf{4 4}}$ the coexisting ions $\left(\mathrm{Mg}^{2+}, \mathrm{Ca}^{2+}, \mathrm{K}^{+}, \mathrm{SO}_{4}{ }^{2-}, \mathrm{Br}^{-}, \mathrm{BO}_{3}{ }^{3-}\right.$, and $\left.\mathrm{VO}_{3}{ }^{-}\right)$were selected for the experiments of uranium(vi) sorption to study the selectivity of $\mathrm{MoS}_{2}$-PVIAO (17.1\%). All the coexisting ions are in the same 
Table 2 Kinetic parameters for the sorption of uranium(VI) by $\mathrm{MoS}_{2}$-sheets, $\mathrm{MoS}_{2}-\mathrm{PVIAO}(10.0 \%$ ) and MoS 2 -PVIAO (17.1\%) (experimental condition: $5.0 \mathrm{~mL}$ solution, $\mathrm{pH} 8.0,0.2 \mathrm{~g} \mathrm{~L}^{-1}$ sorbent dose, $5.0 \times 10^{-5} \mathrm{~mol} \mathrm{~L}^{-1}$ uranium(vI) and $298.15 \mathrm{~K}$ )

\begin{tabular}{|c|c|c|c|c|c|c|c|}
\hline Sample & $q_{\mathrm{e}, \exp }\left(\mathrm{mg} \mathrm{g}^{-1}\right)$ & $k_{1}\left(\mathrm{~s}^{-1}\right)$ & $q_{\mathrm{e}, \mathrm{cal}}\left(\mathrm{mg} \mathrm{g}^{-1}\right)$ & $R^{2}$ & $k_{2}\left(\mathrm{~g} \mathrm{mg}^{-1} \mathrm{~s}^{-1}\right)$ & $q_{\mathrm{e}, \mathrm{cal}}\left(\mathrm{mg} \mathrm{g}^{-1}\right)$ & $R^{2}$ \\
\hline $\mathrm{MoS}_{2}$-PVIAO (10.0\%) & 20.42 & 0.167 & 32.81 & 0.878 & 0.015 & 21.44 & 0.999 \\
\hline $\mathrm{MoS}_{2}$-PVIAO (17.1\%) & 58.75 & 0.105 & 34.13 & 0.875 & 0.005 & 61.80 & 0.998 \\
\hline
\end{tabular}

Table 3 Langmuir and Freundlich parameters for uranium(VI) sorption by $\mathrm{MoS}_{2}$-sheets, $\mathrm{MoS}_{2}$-PVIAO (17.1\%) and MoS 2 -PVIAO (53.7\%) (experimental condition: $5.0 \mathrm{~mL}$ solution, $\mathrm{pH} 8.0,0.2 \mathrm{~g} \mathrm{~L}^{-1}$ sorbent dose and $298.15 \mathrm{~K}$ )

\begin{tabular}{|c|c|c|c|c|c|c|}
\hline Sorbent & \multicolumn{3}{|l|}{ Langmuir } & \multicolumn{3}{|l|}{ Freundlich } \\
\hline $\mathrm{MoS}_{2}$-PVIAO (17.1\%) & 178.6 & 0.133 & 0.967 & 59.78 & 4.127 & 0.954 \\
\hline $\mathrm{MoS}_{2}$-PVIAO (53.7\%) & 348.4 & 0.249 & 0.964 & 121.5 & 3.758 & 0.962 \\
\hline
\end{tabular}

concentration as those in the seawater. ${ }^{33,45}$ The distribution ratio $\left(K_{\mathrm{d}}\right)$ can be calculated by eqn $(3)$ :

$$
K_{\mathrm{d}}=\frac{C_{0}-C_{\mathrm{e}}}{C_{\mathrm{e}}} \times \frac{V}{m}
$$

where $C_{0}$ and $C_{\mathrm{e}}\left(\mathrm{mg} \mathrm{L}^{-1}\right)$ are the concentrations of uranium(vi) in solution before and after sorption, respectively. $V(\mathrm{~L})$ represents the solution volume and $m(\mathrm{~g})$ is the mass of the sorbent.

The uranium(vi) uptake and the distribution ratio were listed in Table 4. The $K_{\mathrm{d}}$ of $\mathrm{MoS}_{2}$-PVIAO (17.1\%) for uranium(vI) was remarkably larger than that of bare $\mathrm{MoS}_{2}$-sheets, indicating the higher sorption selectivity for $\mathrm{MoS}_{2}$-PVIAO (17.1\%). This result may be attributed to positive charges of PVIAO that can repel the other cations, which improves the selectivity for uranium(vi). It was also noticed that the uranium(vi) uptake decreased to some extent when $\mathrm{Mg}^{2+}, \mathrm{Ca}^{2+}$ and $\mathrm{VO}_{3}{ }^{-}$existed, which may be attributed to the chemisorption of sulfur with the ions.

To study the effect of salinity on uranium(vi) sorption, different concentrations of $\mathrm{NaCl}\left(10^{-4}\right.$ to $\left.10^{-1} \mathrm{~mol} \mathrm{~L}^{-1}\right)$ were added for uranium(vi) sorption experiments. The result was depicted in Fig. 3D. The material remained a high sorption efficiency (76.8\%) even at high salinity $\left(0.1 \mathrm{~mol} \mathrm{~L}^{-1} \mathrm{NaCl}\right)$, implying that the sorbent had a good salt resistance.

\section{Regeneration studies}

Regenerability is important for an effective and economical sorbent. In this study, the reusability of the sorbent was evaluated by five cycles of sorption/desorption using $0.1 \mathrm{~mol} \mathrm{~L}^{-1} \mathrm{HCl}$ and $1.0 \mathrm{~mol} \mathrm{~L}^{-1} \mathrm{NaHCO}_{3}$ solution as eluents, respectively. The results were shown in Fig. 4A. There was only a slight decrease of cycle efficiency (CE) after five cycles using $\mathrm{HCl}$ or $\mathrm{NaHCO}_{3}$ as eluents. In addition, elemental analysis was conducted for the sorbent after five cycles with $0.1 \mathrm{~mol} \mathrm{~L}^{-1} \mathrm{HCl}$ eluent, and the result showed the nitrogen content slightly varied from $6.47 \%$ to $5.27 \%$ (Table $\mathrm{S} 2$, ESI $\dagger$ ). The result might be attributed to a small amount of polymer on $\mathrm{MoS}_{2}$-sheets by Coulomb interaction, which could be washed off by $\mathrm{HCl}$ solution. To evaluate structure transformation of the sorbents, the sorbents after five cycles were characterized by FT-IR (Fig. S8, ESI $\dagger$ ), and no obvious change was observed in material structure after elution with $\mathrm{HCl}$ and $\mathrm{NaHCO}_{3}$.

Table 4 Sorption of uranium(VI) on $\mathrm{MoS}_{2}$-sheets and $\mathrm{MoS}_{2}-\mathrm{PVIAO}(17.1 \%)$ in the presence of coexisting ions (experimental condition: $5.0 \mathrm{~mL}$ solution, $\mathrm{pH} 8.0,0.2 \mathrm{~g} \mathrm{~L}^{-1}$ sorbent dose, a certain concentration of other ions, $5.0 \times 10^{-5} \mathrm{~mol} \mathrm{~L}^{-1}$ uranium(vI) and $298.15 \mathrm{~K}$ )

\begin{tabular}{|c|c|c|c|c|c|c|}
\hline \multirow[b]{2}{*}{ No. } & \multirow[b]{2}{*}{ Salt added } & \multirow[b]{2}{*}{$\begin{array}{l}\text { Concentration } \\
\mathrm{mol} \mathrm{L}^{-1}\end{array}$} & \multicolumn{2}{|c|}{ Uranium(vi) uptake $\left(\mathrm{mg} \mathrm{g}^{-1}\right)$} & \multicolumn{2}{|c|}{$\underline{\text { Distribution ratio } K_{\mathrm{d}}\left(\mathrm{L} \mathrm{g}^{-1}\right)}$} \\
\hline & & & $\mathrm{MoS}_{2}$-sheets & $\begin{array}{l}\mathrm{MoS}_{2} \text {-PVIAO } \\
(17.1 \%)\end{array}$ & $\mathrm{MoS}_{2}$-sheets & $\begin{array}{l}\mathrm{MoS}_{2} \text {-PVIAO } \\
(17.1 \%)\end{array}$ \\
\hline 1 & Not added & - & 15.52 & 51.66 & 2.431 & 142.0 \\
\hline 2 & $\mathrm{MgCl}_{2}$ & $5.2 \times 10^{-2}$ & 6.701 & 39.92 & 0.856 & 17.46 \\
\hline 3 & $\mathrm{Na}_{2} \mathrm{SO}_{4}$ & $2.7 \times 10^{-2}$ & 10.31 & 51.00 & 1.429 & 117.3 \\
\hline 4 & $\mathrm{CaCl}_{2}$ & $9.9 \times 10^{-3}$ & 9.344 & 40.57 & 1.238 & 17.32 \\
\hline 5 & $\mathrm{KCl}$ & $9.7 \times 10^{-3}$ & 13.10 & 48.38 & 1.974 & 63.66 \\
\hline 6 & $\mathrm{KBr}$ & $8.0 \times 10^{-4}$ & 11.99 & 51.18 & 1.729 & 128.6 \\
\hline 7 & $\mathrm{H}_{3} \mathrm{BO}_{3}$ & $4.0 \times 10^{-4}$ & 11.41 & 44.87 & 1.592 & 133.4 \\
\hline 8 & $\mathrm{NH}_{4} \mathrm{VO}_{3}$ & $5.1 \times 10^{-5}$ & 14.84 & 30.22 & 0.924 & 43.51 \\
\hline
\end{tabular}



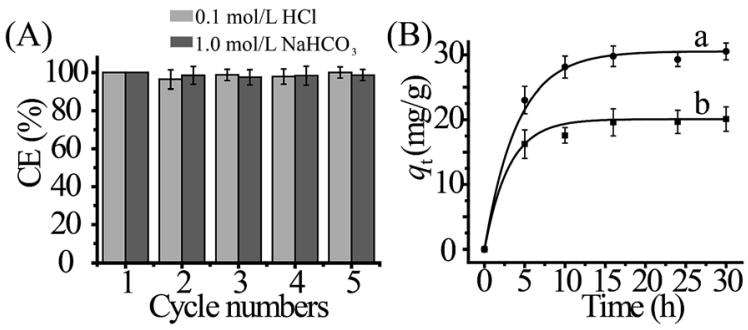

Fig. 4 (A) Recycling of $\mathrm{MOS}_{2}$-PVIAO (17.1\%) in the uranium(VI) sorption with different eluents: $0.1 \mathrm{~mol} \mathrm{~L} \mathrm{~L}^{-1} \mathrm{HCl}$ and $1.0 \mathrm{~mol} \mathrm{~L}{ }^{-1} \mathrm{NaHCO}_{3}$ (experimental condition: $10.0 \mathrm{~mL}$ solution, $\mathrm{pH} 8.0,3.0 \mathrm{mg}$ sorbent, $5.0 \times 10^{-5} \mathrm{~mol} \mathrm{~L}^{-1}$ uranium(VI) and $\left.298.15 \mathrm{~K}\right)$. (B) The sorption amount of uranium(VI) with different period of contact time in simulated seawater: (a) without calcium ions, and (b) with $0.01 \mathrm{mmol} \mathrm{L}^{-1}$ calcium ions (experimental condition: $5.0 \mathrm{~mL}$ solution, $\mathrm{pH} 8.0,0.2 \mathrm{~g} \mathrm{~L}^{-1}$ sorbent dose, $0.034 \mathrm{mmol} \mathrm{L}^{-1}$ uranium(v), $0.438 \mathrm{~mol} \mathrm{~L}^{-1}$ of $\mathrm{NaCl}$, $2.297 \mathrm{mmol} \mathrm{L}^{-1}$ of $\mathrm{NaHCO}_{3}$ and $298.15 \mathrm{~K}$ ).

\section{Test with simulated seawater}

Considering $\left[\mathrm{UO}_{2}\left(\mathrm{CO}_{3}\right)_{3}\right]^{4-}$ is the dominant form of uranium(vI) in seawater, simulated seawater experiments were conducted in this study. The influence of contact time $(t)$ on sorption amount $\left(q_{t}\right)$ was shown in Fig. 4B. It can be found that even at a lower uranium concentration with high salinity, the sorbent also can capture uranium(vI) within $10 \mathrm{~h}$ with a capacity of $28.6 \mathrm{mg} \mathrm{g}^{-1}$ at pH 8.0 and $298.15 \mathrm{~K}$ (Fig. 4Ba). When $\mathrm{Ca}^{2+}$ ions were present at the concentration of $0.01 \mathrm{mmol} \mathrm{L}^{-1}, q_{\max }$ was slightly reduced from $28.6 \mathrm{mg} \mathrm{g}^{-1}$ to $20.1 \mathrm{mg} \mathrm{g}^{-1}$ (Fig. $4 \mathrm{Bb}$ ), which may be due to the formation of the specie $\mathrm{Ca}_{2}\left(\mathrm{UO}_{2}\right)\left(\mathrm{CO}_{3}\right)_{3} \cdot{ }^{46,47}$ The results indicated the sorbent may be used as a promising candidate for potential uranium(vi) extraction from seawater.

\section{Conclusions}

In summary, we show the amidoximated poly(vinyl imidazole)functionalized $\mathrm{MoS}_{2}$ sheets for efficient capture of uranyl tricarbonate complex from aqueous solutions. The sorbent was prepared by grafting amidoximated poly(vinyl imidazole) onto $\mathrm{MoS}_{2}$-sheets. The effects of sorbent dose, sorption kinetics and isotherms, coexisting ions and salinity on uranium(vi) sorption were studied. The sorption follows pseudo-second-order kinetics model with larger rate constant, and the equilibrium can be reached within $30 \mathrm{~s}$. The maximum sorption capacity can reach $348.4 \mathrm{mg} \mathrm{g}^{-1}$ at $\mathrm{pH} 8.0$ and 298.15 K. The $\mathrm{MoS}_{2}$-PVIAO (17.1\%) showed higher selectivity towards uranium(vI) over coexisting ions in comparison with $\mathrm{MoS}_{2}$-sheets. In addition, the sorbent exhibited remarkable salt-resistant stability and could be regenerated efficiently after five cycles with high sorption efficiency. As far as we know, this is the first report on $\mathrm{MoS}_{2}$-sheets for sorption of radionuclides from aqueous solution. This work demonstrates that $\mathrm{MoS}_{2}$-sheets can be used as the promising matrix materials for the separation of radionuclide from aqueous solution.

\section{Acknowledgements}

This work is supported by Natural Science Foundation of China (U1532111, 91326202), a Project Funded by the Priority
Academic Program Development of Jiangsu Higher Education Institutions (PAPD), and Jiangsu Key Laboratory of Radiation Medicine and Protection.

\section{References}

1 Uranium 2011, Resourses, Production and Demand, NEA No. 7059, Organisation for Economic Co-operation and Development/Nuclear Energy Agency, International Atomic Energy Agency, 2012.

2 Y. Lu, Nat. Chem., 2014, 6, 175-177.

3 R. V. Davies, J. Kennedy, R. W. Mcilroy, R. Spence and K. M. Hill, Nature, 1964, 203, 1110-1115.

4 D. Beltrami, G. Cote, H. Mokhtari, B. Courtaud, B. A. Moyer and A. Chagnes, Chem. Rev., 2014, 114, 12002-12023.

5 F. P. Carvalho, J. M. Oliveira, I. Lopes and A. Batista, J. Environ. Radioact., 2007, 98, 298-314.

6 M. J. Manos and M. G. Kanatzidis, J. Am. Chem. Soc., 2012, 134, 16441-16446.

7 A. Baeza, M. Fernandez, M. Herranz, F. Legarda, C. Miro and A. Salas, Water, Air, Soil Pollut., 2006, 173, 57-69.

8 T. P. Rao, P. Metilda and J. M. Gladis, Talanta, 2006, 68, 1047-1064.

9 A. Dâas and O. Hamdaoui, J. Membr. Sci., 2010, 355, 214.

10 I. Tabushi, Y. Kobuke and T. Nishiya, Nature, 1979, 280, 665666.

11 Y. F. Yue, X. G. Sun, R. T. Mayes, J. Kim, P. F. Fulvio, Z. A. Qiao, S. Brown, C. Tsouris, Y. Oyola and S. Dai, Sci. China: Chem., 2013, 56, 1510-1515.

12 J. Gorka, R. T. Mayes, L. Baggetto, G. M. Veith and S. Dai, J. Mater. Chem. A, 2013, 1, 3016-3026.

13 S. Das, S. Brown, R. T. Mayes, C. J. Janke, C. Tsouris, L. J. Kuo, G. Gill and S. Dai, Chem. Eng. J., 2016, 298, 125-135.

14 T. S. Anirudhan, A. R. Tharun, S. Rijith and P. S. Suchithra, J. Appl. Polym. Sci., 2011, 122, 874-884.

15 Y. B. Sun, C. C. Ding, W. C. Cheng and X. K. Wang, J. Hazard. Mater., 2014, 280, 399-408.

16 Y. B. Sun, D. D. Shao, C. L. Chen, S. B. Yang and X. K. Wang, Environ. Sci. Technol., 2013, 47, 9904-9910.

17 L. Shao, X. F. Wang, Y. M. Ren, S. F. Wang, J. R. Zhong, M. F. Chu, H. Tang, L. Z. Luo and D. H. Xie, Chem. Eng. J., 2016, 286, 311-319.

18 S. L. Ma, L. Huang, L. J. Ma, Y. Shim, S. M. Islam, P. L. Wang, L. D. Zhao, S. C. Wang, G. B. Sun, X. J. Yang and M. G. Kanatzidis, J. Am. Chem. Soc., 2015, 137, 3670-3677.

19 L. J. Ma, Q. Wang, S. M. Islam, Y. C. Liu, S. L. Ma and M. G. Kanatzidis, J. Am. Chem. Soc., 2016, 138, 2858-2866.

20 L. Zhou, M. Bosscher, C. S. Zhang, S. Ozcubukcu, L. Zhang, W. Zhang, C. J. Li, J. Z. Liu, M. P. Jensen, L. H. Lai and C. He, Nat. Chem., 2014, 6, 236-241.

21 M. Carboni, C. W. Abney, S. Liu and W. Lin, Chem. Sci., 2013, 4, 2396-2402.

22 J. Kim, C. Tsouris, R. T. Mayes, Y. Oyola, T. Saito, C. J. Janke, S. Dai, E. Schneider and D. Sachde, Sep. Sci. Technol., 2013, 48, 367-387.

23 Y. P. V. Subbaiah, K. J. Saji and A. Tiwari, Adv. Funct. Mater., 2016, 26, 2046-2069. 
24 J. Q. Liu, Z. Y. Zeng, X. H. Cao, G. Lu, L. H. Wang, Q. L. Fan, W. Huang and H. Zhang, Small, 2012, 8, 3517-3522.

25 L. Liao, J. Zhu, X. J. Bian, L. N. Zhu, M. D. Scanlon, H. H. Girault and B. H. Liu, Adv. Funct. Mater., 2013, 23, 5326-5333.

26 L. Rapoport, N. Fleischer and R. Tenne, J. Mater. Chem., 2005, 15, 1782-1788.

27 T. Y. Wang, L. Liu, Z. W. Zhu, P. Papakonstantinou, J. B. Hu, H. Y. Liu and M. X. Li, Energy Environ. Sci., 2013, 6, 625-633. 28 J. N. Coleman, M. Lotya, A. O'Neill, S. D. Bergin, P. J. King, U. Khan, K. Young, A. Gaucher, S. De, R. J. Smith, I. V. Shvets, S. K. Arora, G. Stanton, H. Y. Kim, K. Lee, G. T. Kim, G. S. Duesberg, T. Hallam, J. J. Boland, J. J. Wang, J. F. Donegan, J. C. Grunlan, G. Moriarty, A. Shmeliov, R. J. Nicholls, J. M. Perkins, E. M. Grieveson, K. Theuwissen, D. W. McComb, P. D. Nellist and V. Nicolosi, Science, 2011, 331, 568-571.

29 H. Cheng, N. Dong, T. Bai, Y. Song, J. Wang, Y. Qin, B. Zhang and Y. Chen, Chemistry, 2016, 22, 4500-4507.

30 Y. H. Chao, W. S. Zhu, X. Y. Wu, F. F. Hou, S. H. Xun, P. W. Wu, H. Y. Ji, H. Xu and H. M. Li, Chem. Eng. J., 2014, 243, 60-67.

31 A. T. Massey, R. Gusain, S. Kumari and O. P. Khatri, Ind. Eng. Chem. Res., 2016, 55, 7124-7131.

32 T. Hiemstra, W. H. V. Riemsdijk, A. Rossberg and K. U. Ulrich, Geochim. Cosmochim. Acta, 2009, 73, 4437-4451.
33 Z. H. Zeng, Y. Q. Wei, L. Shen and D. B. Hua, Ind. Eng. Chem. Res., 2015, 54, 8699-8705.

34 Y. Wei, J. Qian, L. Huang and D. Hua, RSC Adv., 2015, 5, 64286-64292.

35 D. B. Hua, L. J. Kuang and H. J. Liang, J. Am. Chem. Soc., 2011, 133, 2354-2357.

36 S. S. Chou, M. De, J. Kim, S. Byun, C. Dykstra, J. Yu, J. X. Huang and V. P. Dravid, J. Am. Chem. Soc., 2013, 135, 4584-4587.

37 A. S. Goloveshkin, I. S. Bushmarinov, A. A. Korlyukov, M. I. Buzin, V. I. Zaikovskii, N. D. Lenenko and A. S. Golub, Langmuir, 2015, 31, 8953-8960.

38 J. T. Lai, A. Debby Filla and R. Shea, Macromolecules, 2002, 35, 6754-6756.

39 K. Saito, K. Uezu, T. Hori, S. Furusaki, T. Sugo and J. Okamoto, AIChE J., 1988, 34, 411-416.

40 Y. S. Ho, J. Hazard. Mater., 2006, 136, 681-689.

41 Y. S. Ho and G. McKay, Chem. Eng. J., 1998, 70, 115-124.

42 M. J. Temkin and V. Pyzhev, Acta Physicochim. URSS, 1940, 12, 217-222.

43 H. Freundlich, Z. Phys. Chem., 1906, 57, 385-470.

44 A. J. Rubin and J. D. Johnson, Anal. Chem., 1967, 39, 298-302. 45 M. Biesalski and J. Ruhe, Macromolecules, 2002, 35, 499-507.

46 A. O. Tirler and T. S. Hofer, Dalton Trans., 2016, 45, 49834988.

47 W. H. Wu, C. Priest, J. W. Zhou, C. J. Peng, H. L. Liu and D. E. Jiang, J. Phys. Chem. B, 2016, 120, 7227-7233. 